\title{
Argentinean Experience in Highways Led Lighting
}

\author{
Pablo Ixtaina ${ }^{1}$, Alejandro Armas ${ }^{1}$, Braian Bannert ${ }^{1} \&$ Nicolás Bufo ${ }^{1}$ \\ ${ }^{1}$ Laboratorio de Acústica y Luminotecnia de la Comisión de Investigaciones Científicas, de la Provincia de \\ Buenos Aires LAL-CIC, Argentina \\ Correspondence: Pablo Ixtaina, LAL-CIC, Camino Centenario y 506 - 1897 Gonnet, Argentina. Tel: \\ 54-221-484-2686.E-mail: pixtaina@unlp.ing.edu.ar
}

Received: April 26, 2017

Accepted: May 4, 2017

Online Published: May 27, 2017

doi:10.5539/eer.v7n1p31

URL: https://doi.org/10.5539/eer.v7n1p31

\begin{abstract}
The impact of led luminaries on road lighting has modified traditional design patterns. The technological change proposes an installation with a higher prime cost and less energy consumption. On the one hand, the price ratio between led luminary and traditional luminary is at least 3:1. On the other, the led better energetic efficiency could allow keeping proper illumination levels with less installed power. In this frame, since mid 2013, the road concessionaires of highways which constitute the Access Network to Buenos Aires city (Argentina), together with Urban Highways of the mentioned city, began a restructuring process of their lighting systems to led technology.

Framed in a review of efficiency concepts and energetic classification for road lighting installations, the work presents the main results of the previous evaluation tests and of the reconverted installations, which can be considered as the first led applications at large scale on road lighting of the region.
\end{abstract}

Keywords: led lighting, highways, energetic efficiency, road lighting, reconversion

\section{Introduction}

The Network of Access to Buenos Aires city (Argentina) consists of four road concessionaries: Acceso Norte, with two main forks, Acceso Oeste, Ezeiza Cañuelas Highway as southern access, and finally Buenos Aires-La Plata highway which links the national capital with the provincial one. This highway network, whose whole trace has artificial lighting, is completed with the also lit Urban Highways of the City, which cross the city and the Avenue General Paz, which surrounds it. The assembly involves around $400 \mathrm{~km}$ of highways whose lighting systems are at several stages of reconversion.

Generally, the network consists of typical highway installations, with central reserve (strip of grass or division "New Jersey" type), from two to six lanes per direction, with spacings ranging from 50 up to $65 \mathrm{~m}$, and mounting heights around $16 \mathrm{~m}$.

The lighting meets Argentinean national Standard: IRAM AADL J 2022-2 (IRAM, 2009), which follows Recommendation CIE 30.2 (Commision Internationale L'Eclairage, 1982). It establishes quality parameters based on luminance summarized in Table 1.

Table 1. Lighting parameters according to IRAM AADL J 2022-2

\begin{tabular}{l|l|l|l|l|l}
\hline \multirow{4}{*}{ Traffic class } & \multicolumn{3}{|l|}{ Minimum allowed values } & & \\
\cline { 2 - 6 } & Average luminance & \multicolumn{2}{|l|}{ Uniformities } & $\begin{array}{l}\text { TI } \\
{[\%]}\end{array}$ & G \\
\cline { 2 - 7 } & $\begin{array}{l}\text { Initial level } \\
{[\mathrm{cd} / \mathrm{m} 2]}\end{array}$ & $\begin{array}{l}\text { Uo } \\
\text { Lmin/Lav }\end{array}$ & $\begin{array}{l}\text { Ul } \\
\text { Lmin/Lmax }\end{array}$ & & \\
\hline A & 2.7 & 0.4 & 0.7 & $\leq 10$ & $\geq 6$ \\
\hline B1 & 2.0 & 0.4 & 0.6 & $\leq 20$ & $\geq 5$ \\
\hline B2 & 1.3 & 0.4 & 0.6 & $\leq 15$ & $\geq 6$ \\
\hline C & 2.7 & 0.4 & 0.6 & $\leq 15$ & $\geq 6$ \\
\hline
\end{tabular}

Note.

A:_Higways, very fast traffic, cars speed $>100 \mathrm{~km} / \mathrm{h}$

B1: Route, maximum speed $<100 \mathrm{~km} / \mathrm{h}$, no lighting surrounding. 
B2: Route, maximum speed $<100 \mathrm{~km} / \mathrm{h}$, lighting surrounding.

C Urban avenues

Initially, the Argentinean highways were considered type A roads, establishing $2.7 \mathrm{~cd} / \mathrm{m} 2$ as mean initial luminance. From the led reconversion process and for the case of urban highways, with maximum speed of 100 or $80 \mathrm{~km} / \mathrm{h}$, it was adopted B1 type, with mean initial luminances of $2.0 \mathrm{~cd} / \mathrm{m} 2$.

The change process was guided by fieldwork lighting studies and laboratory tests carried out by LAL, Official Laboratory from Buenos Aires province. The former were based on standardized luminance measurements (IRAM, 2009), performed on "control zones". These took place on a straight section of the road, chosen due to the readily traffic deviation or interruption, pavement homogeneity and easy access. In such section, the luminaries were replaced by those to be evaluated, on four or eight consecutive columns, adopting the spacing between the two central columns as "evaluation area". These tests, which began in 2011, together with the initial evaluations of the installations already reconverted (2014-2015), form the performance database of led luminaries in highways used in the present work and it was completed with the photometric studies performed to the luminaries.

\section{Led In Road Lighting}

We can sum up the changes introduced by the use of led luminaries in road lighting as follows:

- Increase in installation efficiency.

- White light

- A spectrum allowing maximizing the mesopic vision.

- Longer installation life.

- Lower maintenance costs.

The first issue will be thoroughly analyzed in point 3 , according to the results gathered in the performed measurement fieldworks. It is evident that the energetic efficiency item may be the central point in the installation reconversion plans and the main promise of led as luminous source.

\subsection{White light}

Without doubts, the white light is preferred by users of public spaces, even in the case of vehicle drivers (road lighting). In this sense, the led white light has a chromatic performance that quite outruns the sources that, due to their efficiency, have been chosen for the last 20 years for public and road lighting (sodium high pressure, predominantly with yellow light). The high led chromatic reproduction allows an excellent color perception in parks, squares, commercial areas, etc., and undoubtedly, this is a significant and irreplaceable advantage in urban environments, parks and green areas.

However, good chromatic reproduction does not mean 'to see well". Regarding this, it must be considered the visual task and the requirement on the lighting system. In road lighting, with the aim of night traffic safety, the concept of "seeing well" is associated to the early detection of obstacles and the suitable orientation in order to avoid accidents. In this sense, IRAM (IRAM, 2009) defines: "The purpose of street lighting is to facilitate those who participate in vehicle traffic the reconnaissance of road surface, its borders, obstacles, accesses, crossings, mobile and static objects on it in order to enable night displacement with minimal risk, making also easier the fast traffic flow". Similar characterizations can be found in literature that today can be considered classical (De Boer, 1967; van Bommel, 1982; Erbay, 1974).

Taking the previous definitions as basis, numerous studies have shown that the monochromatic contrast or with limited lighting spectra enables the obstacle detection, improving the sensation of road brightness (van Bommel, 1982; Boer, 1960; Blackwell, 1977). Therefore, it is not proved that white light, though preferred, improves vision under road lighting precepts.

\subsection{Mesopic Vision}

The human vision system has two kinds of receptors in the retina, cones and rods. The former are responsible for the so-called "day vision" or photopic, whose spectral sensitivity (standardized) $V \lambda$ is the basis for defining light, with a maximum in $555 \mathrm{~nm}$. For very low lighting levels, the latter (rods) acquire the main role in the so-called "night vision" or scotopic. The sensitivity curve for rods adopts the same shape as that photopic, but it is displaced towards blue in $55 \mathrm{~nm}$. 
The mesopic vision is an intermediate situation between photopic and scotopic visions, which occurs in lighting situations without reaching the complete darkness or reaching the broad daylight, either.

In road lighting, the luminance values, involved in the driver's vision, can be classified as mesopic (Moon, 1936). In these conditions, shifting the eye spectral sensitivity towards blue may produce certain perceptive gain, thanks to the led spectrum, which has strong components in this region.

Kostic (Kostic, 2013) quantifies the perceptive improvement by considering the eye sensitivity increase in mesopic vision. Table 2, taken from his publication, allows obtaining the equivalent mesopic luminance in a simple way for a certain photopic luminance (measurable), in function of the spectrum relationship scotopic-photopic of the source (relationship S/P). The relationship S/P can be obtained from the source spectrum, for example, $\mathrm{S} / \mathrm{P} \approx 0.65$ for the typical spectrum of high pressure sodium lamps.

Table 2. Corrected photopic luminance, considering mesopic vision (reference S/P 0,65 -SAP-) - taken from (Kostic, 2013)

\begin{tabular}{l|llllll} 
& \multicolumn{6}{|c}{ Photopic luminance $[\mathrm{cd} / \mathrm{m} 2]$} \\
\hline S/P & $\mathbf{0 . 3 0}$ & $\mathbf{0 . 5 0}$ & $\mathbf{0 . 7 5}$ & $\mathbf{1 . 0 0}$ & $\mathbf{1 . 5 0}$ & $\mathbf{2 . 0 0}$ \\
\hline $\mathbf{0 . 2 5}$ & 0.33 & 0.54 & 0.80 & 1.05 & 1.56 & 2.05 \\
$\mathbf{0 . 3 5}$ & 0.32 & 0.53 & 0.79 & 1.04 & 1.54 & 2.04 \\
$\mathbf{0 . 4 5}$ & 0.32 & 0.52 & 0.77 & 1.02 & 1.53 & 2.03 \\
$\mathbf{0 . 5 5}$ & 0.31 & 0.51 & 0.76 & 1.01 & 1.52 & 2.02 \\
$\mathbf{0 . 6 5}$ & 0.30 & 0.50 & 0.75 & 1.00 & 1.50 & 2.00 \\
$\mathbf{0 . 7 5}$ & 0.29 & 0.49 & 0.74 & 0.99 & 1.49 & 1.99 \\
$\mathbf{0 . 8 5}$ & 0.29 & 0.48 & 0.73 & 0.98 & 1.48 & 1.98 \\
$\mathbf{0 . 9 5}$ & 0.28 & 0.48 & 0.72 & 0.97 & 1.47 & 1.97 \\
$\mathbf{1 . 0 5}$ & 0.27 & 0.47 & 0.71 & 0.96 & 1.46 & 1.96 \\
$\mathbf{1 . 1 5}$ & 0.27 & 0.46 & 0.70 & 0.94 & 1.44 & 1.95 \\
$\mathbf{1 . 2 5}$ & 0.26 & 0.45 & 0.69 & 0.93 & 1.43 & 1.94 \\
$\mathbf{1 . 3 5}$ & 0.26 & 0.45 & 0.68 & 0.92 & 1.42 & 1.92 \\
$\mathbf{1 . 4 5}$ & 0.25 & 0.44 & 0.68 & 0.91 & 1.41 & 1.91 \\
$\mathbf{1 . 5 5}$ & 0.25 & 0.43 & 0.67 & 0.91 & 1.40 & 1.90 \\
$\mathbf{1 . 6 5}$ & 0.24 & 0.42 & 0.66 & 0.90 & 1.39 & 1.89 \\
$\mathbf{1 . 7 5}$ & 0.24 & 0.42 & 0.65 & 0.89 & 1.38 & 1.88 \\
$\mathbf{1 . 8 5}$ & 0.23 & 0.41 & 0.64 & 0.88 & 1.37 & 1.87 \\
$\mathbf{1 . 9 5}$ & 0.23 & 0.41 & 0.63 & 0.87 & 1.36 & 1.86 \\
$\mathbf{2 . 0 5}$ & 0.23 & 0.40 & 0.63 & 0.86 & 1.35 & 1.85 \\
$\mathbf{2 . 1 5}$ & 0.22 & 0.39 & 0.62 & 0.85 & 1.34 & 1.84 \\
$\mathbf{2 . 2 5}$ & 0.22 & 0.39 & 0.61 & 0.84 & 1.33 & 1.83 \\
$\mathbf{2 . 3 5}$ & 0.21 & 0.38 & 0.61 & 0.83 & 1.32 & 1.82 \\
$\mathbf{2 . 4 5}$ & 0.21 & 0.38 & 0.60 & 0.83 & 1.31 & 1.81 \\
$\mathbf{2 . 5 5}$ & 0.21 & 0.37 & 0.59 & 0.82 & 1.30 & 1.80 \\
$\mathbf{2 . 6 5}$ & 0.20 & 0.37 & 0.58 & 0.81 & 1.29 & 1.79 \\
$\mathbf{2 . 7 5}$ & 0.20 & 0.36 & 0.58 & 0.80 & 1.28 & 1.78 \\
\hline & & & & & &
\end{tabular}

Table 2 was built using the sodium spectrum as a reference, that is way for $\mathrm{S} / \mathrm{P}=0.65$ the actual luminance (photopic luminance) is the same that the mesopic luminance shown in the table (shaded row in table 2). In order to give an example of the effect of the mesopic vision in a highway, we can consider an installation with cold white led $(\mathrm{S} / \mathrm{P} \approx 1.85)$. According to table 2 , in such installation, a medium luminance of $0.88 \mathrm{~cd} / \mathrm{m} 2$ could have the same visual effect as $1.0 \mathrm{~cd} / \mathrm{m} 2$ achieved with a sodium spectrum ( $\mathrm{S} / \mathrm{P}=0.65$ for SAP lamps), due the observer is in "mesopic vision". The difference becomes minimal for higher luminances, that is to say, if we consider our standard (IRAM, 2009: $\mathrm{Lav}=2.7 \mathrm{~cd} / \mathrm{m} 2$ ), the influence of the mesopic vision is practically negligible (right side of the table 2).

\subsection{Life and Maintenance}

The actual data that could be collected at this stage have a relative significance due to the fairly short time of use of the new installations. The local reconversions to which we had access were made between ends 2014 and 
2016. Taking into account $3600 \mathrm{~h} /$ year for the mean switch-on timing of a road lighting installation, the local installations have less than 8000 hour of use, so they not exceed $20 \%$ of the lifetime promised for leds of 50,000 h. Besides, the data provided by manufacturers (figure 1, taken from CREE leds data sheet as example) are based on short term measurements (5000 h) and extrapolations.

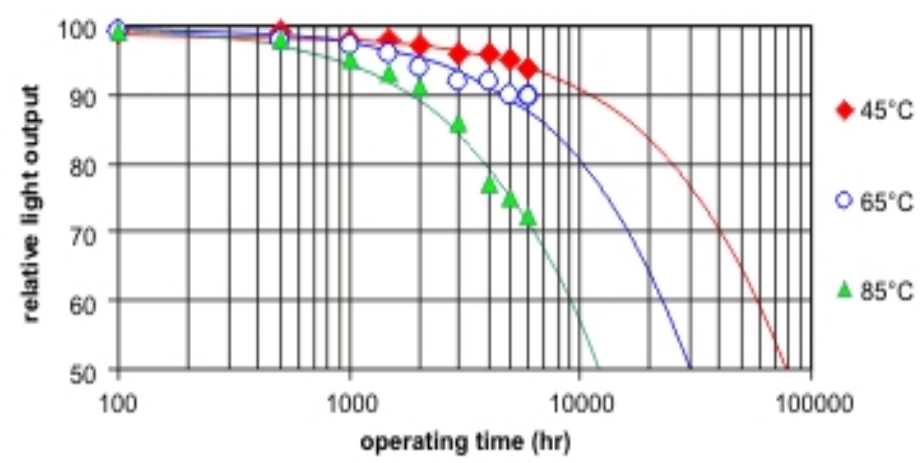

Figure 1. Life and depreciation of led modules, taken from CREE data sheet

Considering figure 1 , and as additional data, the led life and depreciation highly depend on the joint temperature inside the actual luminary, also difficult to estimate, that is why the performance of current installations will provide true data in a few years time.

\section{Energetic Efficiency}

Considering the diagram of figure 2 , the mean luminance that a conventional luminary produces can be obtained from(1).

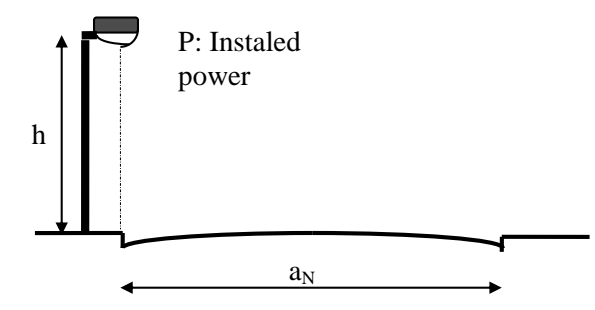

S

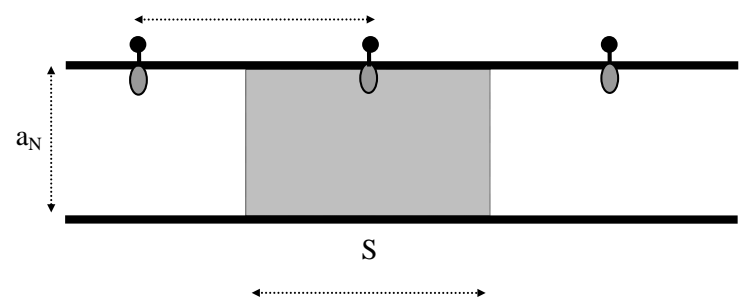

Figure 2. Elementary road diagram.

$$
\mathrm{L}=\mathrm{Qo} \mu_{\mathrm{u}} \frac{\mathrm{LOR} \mu_{\mathrm{L}} \mu_{\mathrm{B}} \mathrm{P}_{\mathrm{LUM}}}{\mathrm{S} \mathrm{a}_{\mathrm{N}}}
$$

In (1), $\mu_{\mathrm{u}}$ is the luminary performance in the installation (relationship between useful luminous flux and flux emitted by luminaries), Qo is the mean luminance coefficient, LOR the luminary performance (luminary output radio), $\mu_{\mathrm{L}}$ is the lamp efficiency, $\mu_{\mathrm{B}}$ is the ballast performance and $\mathrm{P}_{\mathrm{LUM}}$ is the luminary power.

In a led luminary, the luminous source (led module) is inseparable from the luminary. The performance is integrated: led module optical system and driver. Thus, (1) should be redeveloped as (2).

$$
\mathrm{L}=\mathrm{Q} o \mu_{\mathrm{u}} \frac{\mu_{\mathrm{LUM}} \mathrm{P}_{\mathrm{LUM}}}{\mathrm{S} \mathrm{a}_{\mathrm{N}}}
$$

The comparison then between led luminary and a conventional luminary should be carried out by comparing (3) 
with (4).

$$
\begin{gathered}
\text { LOR } \mu_{\mathrm{L}} \mu_{\mathrm{B}} \\
\mu_{\mathrm{LUM}}
\end{gathered}
$$

Table 3 shows typical data of luminaries, lamps and auxiliary equipment installed in our country and assessed in the LAL.

Table 3. Typical parameters of conventional luminaries

\begin{tabular}{c|c}
\hline Luminaries - LOR & $0.75-0.85$ \\
Lamp - $\eta_{\mathrm{L}}$ & $120 \mathrm{~lm} / \mathrm{W}-140 \mathrm{~lm} / \mathrm{W}$ \\
Ballast $-\eta_{\mathrm{B}}$ & $0.90-0.95$ \\
\hline
\end{tabular}

LOR $=0.75$ is the minimum value admitted by the Argentinean program for financing lighting installations (PRONUREE, 2007). Higher values can be achieved in luminaries with cared optics and transparent closing. Similar considerations are good for the rest of the parameters. For instance, $120 \mathrm{Lm} / \mathrm{W}$ corresponds to a high pressure sodium lamp of regular use, $140 \mathrm{~lm} / \mathrm{W}$ corresponds to state of the art SAP lamps and also to those known as "ceramic sodium", of white light.

As regards led luminaries, the collected data are summarized in figure 3.

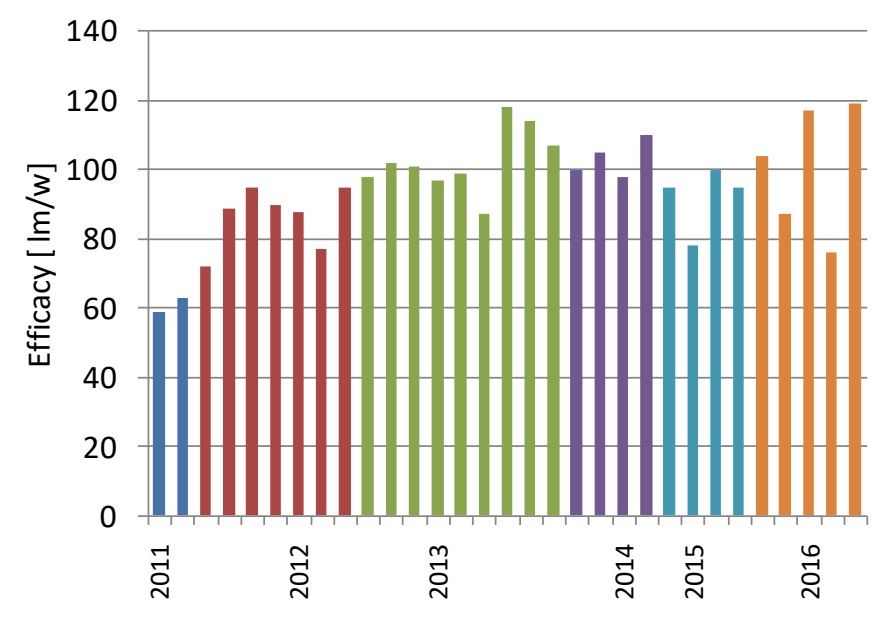

Figure 3. Efficacy of led luminaries

In relation to figure 3, the presented data correspond to luminaries measured in LAL. It is shown marketed luminaries and also prototypes or previous tests that possibly did not reach the market. This comment mainly refers to the period 2011/2013. The diagram bars do not have a true correlation with an amount of luminaries, the indicated values are those characteristic of each period. The test average of is around 15/20 annual photometries, except for 2013, when the average was exceeded for the very reason of assisting companies which tested several prototypes.

Even though figure 3 shows a decreasing tendency for the effic acy of led luminaries for the period 2011-2014, it is observed certain present stability, with values between $90 \mathrm{~lm} / \mathrm{W}$ and almost $120 \mathrm{~lm} / \mathrm{W}$.

For conventional luminaries and taking values shown in table 3, the efficiencies shown in table 4 are obtained.

Table 4. Efficacy of conventional luminaries.

\begin{tabular}{cl}
\hline $\mathbf{L O R} \mu_{\mathbf{L}} \mu_{\mathbf{B}}$ & \\
\hline $0,75 \times 120 \mathrm{~lm} / \mathrm{W} \times 0.90$ & $81 \mathrm{~lm} / \mathrm{W}$ \\
$0,85 \times 140 \mathrm{~lm} / \mathrm{W} \times 0.95$ & $113 \mathrm{~lm} / \mathrm{W}$ \\
\hline
\end{tabular}


Comparing the average of the efficiency ranges for each type of luminary; led luminaries are around 7\% more advantageous than luminaries with discharge lamps. About this last comparison, it should be noted that a led luminary not necessarily is equivalent to that most efficient, since there are several led technologies in the market, some of which result in less efficient luminaries than those traditional with SAP.

\subsection{Efficiency in the Installation}

Normalized power density

In order to quantify the efficiency of an installation, the normalized power density NP is defined as the installed power per unit of road area (figure2) in relation to the lighting level produced.

$$
\mathrm{P}_{\mathrm{N}}=\frac{\mathrm{P}_{\mathrm{D}}}{\mathrm{L}_{\mathrm{m}}}=\frac{\mathrm{P}}{\mathrm{S} \mathrm{a}_{\mathrm{N}} \mathrm{L}_{\mathrm{m}}}
$$

In (5), $L_{m}$ is the average luminance on road. The normalized power density PN result expressed in W/m2/cd/m2

Pracki (Pracki, 2011) developed a project of energetic classification for road lighting installations. His study was based on simulation, by means of software, of several installation alternatives: two geometries, dark and light standard road surface, two typical ways of luminous arrangement of luminaries and varied efficiencies of lamps. The achieved combinations resulted in a range of possible values of PN, which later was used for qualifying energetically the installation.

Table 5, taken from the cited reference, shows the proposed classification system, which qualifies the installations in seven levels according to their normalized power, form the highest efficiency (type A) to the lowest (Type F).

Table 5. Classification in function of the normalized power.

\begin{tabular}{llc}
\hline & Type of energetic efficiency & $\begin{array}{c}\mathbf{P}_{\mathbf{N}} \\
\mathbf{N} / \mathbf{m}^{2} / \mathbf{c d} / \mathbf{m}^{2}\end{array}$ \\
\hline A & The highest energetic efficiency & $<0.2$ \\
B & Very efficient & $0.2-0.4$ \\
C & Efficient & $0.4-0.6$ \\
D & Medium efficient & $0.6-0.8$ \\
E & Little efficient & $0.8-1.0$ \\
F & Highly inefficient & $1.0-1.2$ \\
G & The least energetic efficiency & $>1.2$ \\
\hline
\end{tabular}

Normalized Power in Argentinean Highways.

In table 6, it is shown the normalized powers obtained from luminance evaluations in urban highways or those of access to Buenos Aires city (Argentina), already cited.

Table 6. Normalized power measured in Argentinean highways

\begin{tabular}{lccc}
\hline Highway & $\begin{array}{c}\text { Lav } \\
{[\mathbf{c d} / \mathbf{m} 2]}\end{array}$ & $\begin{array}{c}\text { Installed } \\
\text { power/column } \\
{[\mathbf{W}]}\end{array}$ & $\begin{array}{c}\mathbf{P}_{\mathbf{N}} \\
{\left[\mathbf{W} / \mathbf{m}^{2} / \mathbf{c d} / \mathbf{m}^{2}\right]}\end{array}$ \\
\hline Led 1 & 2.30 & 416 & 0.29 \\
Led 2 & 3.79 & 270 & 0.23 \\
Led 3 & 2.15 & 570 & 0.32 \\
Led 4 & 2.11 & 570 & 0.38 \\
SAP 400 & 4.34 & 440 & 0.27 \\
SAP 400 & 2.32 & 880 & 0.36 \\
SAP & 5.20 & 880 & 0.33 \\
\hline
\end{tabular}

All the evaluations were carried out according to methods standardized by IRAM (IRAM, 2009). All led installations reconverted in the period 2013/2015 (measurements in initial state) and typical values of the same installations with traditional lighting (high pressure sodium) are included. The latter correspond to neglected systems. All considered evaluations take into account, for the led case, stations keeping the same geometrical parameters (openings, assembly height, etc.), that is, the reconversion only included change of luminaries. 
It is observed that all installations kept a classification Type "B" - "Very efficient", however, the use of leds did not produce great differences in the normalized power. There was even a case that efficiency worsened with the use of leds.

\section{Conclusions}

The use of leds in highways is not showing a substantial increase in energetic efficiency. In this sense, the enhancement of $7 \%$ on average found for the efficacy of led luminaries is not evident in the studied installations, which practically keep index PN without changes. Although it is true that the new installations reduce the energetic consumption, it is to achieve medium luminance levels closer to those regulated by IRAM (IRAM, 2009). In other words, the studied led lighting installations mark a tendency to reinforce the control of over dimensioning more than increase the efficiency.

Two aspects should be taken into account: On one side, the new leds luminaries (2017) have increased their efficacy to $140 \mathrm{~lm} / \mathrm{W}$, showing a new trend. On the other hand, the studied "lamp to led" reconversions did not make an integral change of the installation. It is likely that the superior efficiency of this new technology can be further exploited if, along with changes in luminaries, the geometrical parameters of the installation (distance between columns, spacing, height, etc.) are optimized according to the photometric curves of new led luminaries.

\section{Acknowledgments}

The authors thank CIC PBA, where P.I. is member of the Scientific and Technological Researcher Career, A.A. and B.B. are professionals and N.B. is technician.

\section{References}

Blackwell, O. M., \& Blackwell, H. R. (1977). A proposed procedure for predicting performance aspects of roadway lighting in terms of visibility. Journal of IES, 6, p. 148.

Boer, J. B. (1960). Investigations on the influence of colour of light on vision in road. Zentralblatt fur Verkehrs-Medizin. Verkehrs Psychologie, 6.

Cree.http://www.cree.com/led-components/media/documents/XLampXPEHEW-8B.pdf

De Boer, J., Cohu, M., \& Schreuder, D. (1967). Public Lighting. Philips Technical Library, The Netherlands.

Erbay, A. (1974). Reflection properties of road surfaces. ILTUB, Berlin.

Instituto Argentino de Racionalización de Materiales, IRAM AADL J 2022-2, Alumbrado Público, Vías de Tránsito - Clasificación y Niveles de Iluminación. Buenos Aires, 1995

Kostic, A. M., Kremic, M. M. Djokic, L. S. \& Kostic, M. B. (2013). Light-emitting diodes in street and roadway lighting - a case study involving mesopic effects. Lighting Research and Technology, 45, 217. https://doi.org/10.1177/1477153512440771

Moon, P. (1936). The Scientific Basis of Illuminating Engineering. McGraw Hill Company, London.

Pracki, P. (2011). A proposal to classify road lighting energy efficiency. Lighting Res. And Technol, 43, 271-280. https://doi.org/10.1177/1477153511407996

PRONUREE, Programa Nacional de Uso Racional y Eficiente de la Energía. Retrieved from http://energia3.mecon.gov.ar/contenidos/verpagina.php?idpagina $=3102$

Publication CIE No 30-2 (TC-4.6), Calculation and measurement of luminance and illuminance in road lighting. Vienna, 1982.

van Bommel, W., \& de Boer, J. (1982). Road Lighting, Philips Technical Library, The Netherlands, 1982.

\section{Copyrights}

Copyright for this article is retained by the author(s), with first publication rights granted to the journal.

This is an open-access article distributed under the terms and conditions of the Creative Commons Attribution license (http://creativecommons.org/licenses/by/4.0/). 